sĩ y học, "Chất lượng cuộc sống và các yếu tố ảnh hưởng đến chất lương cuốc sống ở bênh nhân động kinh Ikuko Laccheo, Elizabeth Ablah, Robin Heinrichs, Toni Sadler, Lyle 5. Baade, Kore Liow (2008), Assessment of quality of life among the elderly with epilepsy, Epilepsy and Behavior, 12, pp. $257-261$

5. Goodridge và S. D. Shorvon (1983). Epileptic seizures in a population of 6.000. Demography, diagnosis and classification. B-M-J 287
6. M. Rathor, M. Shahar, A. Omar et al (2017). Assessment of Knowledge, attitude and practices of Epilepsy Patients towards their illness and treatment in a tertiary care hospital in Kuantan Pahang Malaysia. Bangladesh. Journal of Medical Science, 16(14):545-553.

7. Mukadder Monl, laoglu Injuries in Patients with Epilepsy and Some Factors Associated with Injury -ncbi

\title{
XÂY DỰNG MÔ HÌNH DƯ BÁO CHI PHÍ CHO ĐIỀU TRI BÊNNH SUY TIM DỰA TRÊN DỮ LIẾU THANH TOÁN BẢO HIỂM Y TẾ TOÀN QUỐC GIÁI ĐOẠN 2017 - 2018
}

\section{TÓM TẮT}

Hiện nay, bệnh suy tim là một vấn đề lớn về y tế và kinh tế đang gia tăng trên toàn thế giới. Chí phí điều trị suy tim đã được thực hiện ở một số quốc gia trên thế giới tuy nhiên chưa có nghiên cứu dự báo chi phí điêu trị suy tim. Phân tích chi phí (CP) trực tiếp y tế (TTYT) trong điều trị suy tim trên mẫu 111.926 người bệnh suy tim dựa trên dữ liệu hồi cứu tại Bảo hiểm xã hội Việt Nam trong giai đoạn 2017 - 2018, đề tài ghi nhận với độ tuổi trung bình $69,71 \pm 15,18$; tỷ lệ nam: nữ là 1: 1,30; số ngày điều trị trung bình tại bệnh viện $11,99 \pm 13,64$ ngày, các yếu tố có liên quan đến tổng chi phí điều trị bao gồm sử dụng thủ thuật phẫu thuật, tuổi người bệnh, giới tính nam, số ngày điều trị, cấp cứu, nội chuyển viện, có tiểu đường, lượt ngoại trú. Mô hình hồi quy tuyến tính đa biến thể hiển mối liên hệ tổng hợp của các yếu tố liên quan đến tổng chi phí điều trị suy tim được xây dựng với $\mathrm{R}^{2}$ hiệu chỉnh là $0,574(\mathrm{p}<0,05)$ và có dang như sau:

LN (Tông chi phí) = 14,503 +0,557 * TTPT + 0,001* Tuôi + 0,053* Nam + 0,045* Số ngày điều tri $+0,095 *$ Cấp cứu $+0,067 *$

Nội chuyên viên + 0,051 * Có tiểu đường + $0,104 *$ Lươt ngoai trú

Tư khóa: Suy tim, chi phí điểu trị, Bảo hiểm xã hội Việt Nam, mô hình, dự báo

\section{SUMMARY \\ CONTRUCT A FORECAST MODEL OF TREATMENT COST FOR HEART FAILURE BASED ON VIETNAMESE HEALTH INSURANCE PAYMENT DATA IN 2017 - 2018 PERIOD}

${ }^{1}$ Đại học Y Dượ TP Hồ Chí Minh

${ }^{2}$ Bảo hiểm xã hội Việt Nam

Chịu trách nhiệm chính: Nguyễn Thị Thu Thủy

Email: nguyenthuthuy@ump.edu.vn

Ngày nhận bài: 18.10.2021

Ngày phản biên khoa hoc: 14.12.2021

Ngày duyệt bài: 21.12.2021
Nguyễn Bá Phát ${ }^{1}$, Nguyễn Ngọc Mai Trúc ${ }^{1}$,
Trần Tiến Hưng ${ }^{2}$, Nguyễn Thị Thu Thuỷ ${ }^{1}$

Currently, heart failure is a major growing health and economic problem worldwide. Treatment cost of heart failure has been analyzed in a number of countries in the world, however where there are no studies predicting duration of treatment failure. Analysis of direct medical costs (CP) during treatment on a sample of 111,926 heart failure patients based on data of Vietnam Social Security in the period 2017 2018 , the study noted with the middle age $69.71 \pm$ 15.18; the male: female ratio is 1 : 1.30 ; average number of days in hospital $11.99 \pm 13.64$ days, factors related to total cost include using technical algorithm, patient age, male gender, number of days value, level up, library of the content, have a small path, extructs. The multivariable computational regression model showing the aggregate relationship of factors related to the total time to adjust the value was built with adjusted R2 of 0.574 ( $p<0.05)$ and has the following form :

LN (Direct medical costs) $=14.503+$

$0.557 *$ Surgical procedures $+0.001 *$ age

$+0.053 *$ male $+0.045 *$ Number of

treatment days $+0.095 *$ emergency +

$0.067 *$ Hospitalization $+0.051 *$ Diabetes $+0.104 *$ Outpatient visits

Keywords: Heart failure, treatment costs, Vietnam Social Insurance.

\section{I. ĐẶT VẤN ĐỀ}

Suy tim là một hội chứng lâm sàng phức tạp do rối loạn cấu trúc hoăc chức năng của tim, làm suy giảm quá trình đổ đầy hoặc tống máu vào tâm thất đối với hệ tuần hoàn [1]. Bệnh suy tim ảnh hưởng đăcc biệt đến người cao tuổi với tỉ lệ $80 \%$ nhập viện liển quan đến bệnh suy tim và $90 \%$ trường hợp tử vong liên quan đến bệnh suy tim xảy ra ở những bệnh nhân từ 65 tuổi trở lên [2]. Suy tim là một vấn đề lớn về y tế và kinh tế 
đang gia tăng trên toàn thế giới với tỷ lệ chiếm $1-2 \%$ ngân sách quốc gia chi cho ngành y tế [2]. Theo cơ quan đăng ký Trao đổi Dũ liệu $Y$ tế Toàn cầu, tỷ lệ hiện mắc suy tim trên toàn thế giới là 64,34 triệu trường hợp. Điều này tương đương với 9,91 triệu năm bị mất do khuyết tật (YLDs) và 346,17 tỷ đô la Mỹ chi phí chăm sóc sức khỏe [3].

Mặc dù, hiệu quả của chăm sóc bệnh suy tim đã được cải thiện rõ rệt và chứng minh về tỷ lệ tử vong giảm đáng kể bằng các liệu pháp. Tuy nhiên, ngoài việc mang lại gánh nặng bệnh tật nghiêm trọng bởi những di chứng nặng nề mà còn gây ra gánh nặng về chi phí y tế ngày một gia tăng. Do đó, cần có các nghiên cứu về chi phí bệnh suy tim là một công cụ quan trọng để phân tích gánh nặng kinh tế của bệnh suy tim nhằm cung cấp thông tin bác sĩ lâm sàng và các nhà hoạch định chính sách y tế. Cho đến nay, đã có nhiều nghiên cứu phân tích chi phí điều trị suy tim trên khắp các quốc gia tại châu Á, châu Âu và châu Mỹ $[4,5]$. Tại Việt Nam, CPTTYT trung bình 1 đợt điêu trị suy tim nội trú được ghi nhận là 8.401.579,63 $\pm 55.111,95$ VND trong nghiển cứu của tác giả Nguyễn Thị Thu Thủy năm 2020 [6]. Để có cái nhìn tổng quát hơn về chi phí điều trị bệnh suy tim tạo cơ sở dự báo chi phí này trong tương lai, đề tài "Xây dựng mô hình dự báo chi phí điều trị bệnh suy tim dựa trên dữ liệu thanh toán bảo hiểm y tế toàn quốc giai đoạn 2017-2018" được thực hiên với các mục tiêu sau: Khảo sát đăc điểm của người bênh suy tim theo dữ liệu bảo hiểm y tế toàn quốc giai đoạn 2017 2018.

1. Phân tích các yếu tố liên quan đến chi phí điều tri bênh suy tim

2. Xây dựng phương trình hồi quy dự báo chi phí điều trị bệnh suy tim.

II. ĐỐl TƯỢNG VÀ PHƯƠNG PHÁP NGHIÊN CỨU

Đối tượng nghiên cứu: $\mathrm{CP}$ TTYT trong điều trị suy tim theo quan điểm người chi trả từ dữ liệu thanh toán điện tử của bảo hiểm xã hội Việt Nam (BHXH VN) toàn quốc giai đoạn 2017 - 2018.

Phương pháp nghiên cứu: Mô tả cắt ngang dựa trên dữ liệu hồi cứu tại Bảo hiểm xã hội Việt Nam trong giai đoạn 2017 - 2018.

Mẫu nghiên cứu: Toàn bộ mẫu trong dữ liệu thanh toán BHXH đáp ứng tiêu chuẩn chọn mẫu.

\section{Tiêu chí lựa chọn}

- Người bệnh suy tim với ICD code I50

- Người bệnh có độ tuổi từ đủ 16 tuổi

- Tham gia bảo hiểm y tế và sử dụng bảo hiểm y tế cho điều trị
- Có thời gian điều trị suy tim trung bình trong 1 năm

\section{Tiêu chí loai trư}

- Người bệnh không đủ dữ liệu cần thiết cho nghiên cứu

- Có ít hơn 3 lần thăm khám ngoại trú và không có nhập viện nội trú trong vòng 1 năm

Thời gian nghiển cứu: Từ $01 / 8 / 2020$ 01/8/2021.

Thống kê và xử lý số liệu: Tất cả số liệu được thu thập vào bảng dữ liệu nghiên cứu Microsolf Excel 2013 và xử lý và thống kê bằng phần mềm IBM SPSS Statistics 20.0 với kết quả được trình bày ở dạng hình và bảng.

\section{KẾT QUẢ NGHIÊN CỨU}

Khảo sát đặc điểm mẫu nghiên cứu. Khảo sát mẫu nghiên cứu bao gồm 111.926 ca suy tim trên dữ liệu BHYT Việt Nam năm 2017-2018 thỏa tiêu chí chọn mẫu, đề tài ghi nhận những đặc điểm nhân khẩu và đặc điểm bệnh lý được trình bày trong bảng 1 .

Bảng 1. Đặc điểm mẫu nghiên cứu

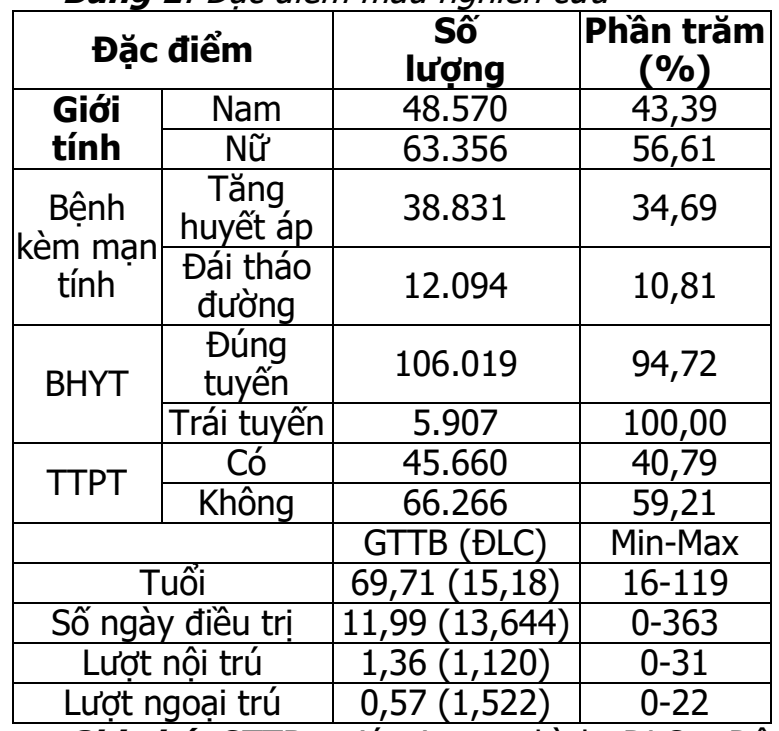

Ghi chú: GTTB - giá trị trung bình, ĐLC - Độ lệch chuẩn

Theo bảng 1 , nghiên cứu ghi nhận độ tuổi trung bình là $69,71 \pm 15,18$ với tỷ lệ nam: nữ là 1: 1,30 , người bệnh có số ngày điều trị trung bình tại bệnh viện là $11,99 \pm 13,644$ ngày với số ngày điều trị ít nhất là 0 ngày, nhiêu nhất là 363 ngày. Người bệnh tham gia BHYT điêuu trị đúng tuyến $94,72 \%$, trái tuyến $5,28 \%$, bệnh nhân suy tim có bệnh lý kèm theo tăng huyết áp chiếm tỷ lệ $34,69 \%$, đái tháo đường chiếm $10,81 \%$. Số lượt điều trị nội trú trung bình trong một năm cho mỗi bệnh nhân là $1,36 \pm 1,12$ lượt, với số 
lượt nôi trú lớn nhất là 31 lượt và nhỏ nhất là 0 lượt. Số lượt điều trị ngoại trú trung bình trong một năm cho mỗi bệnh nhân là $0,57 \pm 1,522$ lượt, với số lượt ngoại trú lớn nhất là 22 lượt và nhỏ nhất là 0 lượt.
Phân tích các yêu tố liên quan đến tổng chi phí điêuu trị suy tim. Phân tích mối liên hệ giữa giá trị CP TTYT mỗi đợt điêu trị suy tim và̀ các yếu tố ảnh hưởng, nghiên cứu thu được kết quả được trình bày trong bảng 3 .

Bảng 3. Yếu tố liên quan đến CP TTYT điều trị suy tim

\begin{tabular}{|c|c|c|c|c|}
\hline \multicolumn{2}{|c|}{ Nhóm tiêu chí } & Chênh lệch CP & 95\% KTC & Trị số p \\
\hline Giới tính & Nam vs Nữ & 2.367 .744 & $2.045 .242-2.690 .247$ & 0,000 \\
\hline Tăng huyết áp & Không vs Có & 3.067 .102 & $2.737 .608-3.396 .596$ & 0,000 \\
\hline Đái tháo đường & Có vs Không & 368.834 & $-67.495-805.164$ & 0,098 \\
\hline Thủ thuật phẫu thuật & Có vs Không & 15.945 .932 & $15.640 .286-16.251 .577$ & 0,000 \\
\hline \multirow{2}{*}{\multicolumn{2}{|c|}{ Nhóm tiêu chí }} & \multicolumn{3}{|c|}{ Tổng chi phí } \\
\hline & & \multicolumn{2}{|c|}{ Hệ số tương quan Pearson } & Trị số p \\
\hline \multicolumn{2}{|l|}{ Tuổi } & \multicolumn{2}{|r|}{$-0,068$} & 0,000 \\
\hline \multicolumn{2}{|c|}{ Số ngày điều tri } & & & 0,000 \\
\hline \multicolumn{2}{|c|}{ Lươt ngoai trú } & \multicolumn{2}{|r|}{$\begin{array}{l}0,428 \\
0,032\end{array}$} & 0,000 \\
\hline
\end{tabular}

Ghi chú: CP - Chi phí, KTC - Khoảng tin cậy

Theo Bảng 4, nghiên cứu ghi nhận người bệnh nam giới có $\mathrm{CP}$ TTYT cao hơn nữ giới 2.367.744 VND (95\%CI: 2.045.242 - 2.690.247; $\mathrm{p}=0,000)$. Về các bênh mắc kèm, người bệnh không có bệnh tăng huyết áp có chi phí điều trị cao hơn người bệnh có bệnh này 3.067.102 VNĐ (95\%CI: 2.737.608 - 3.396.596; $p=0,000$ ). Ngược lại, người bệnh mắc bệnh đái tháo đường có tổng chi phí điều trị cao hơnn người không có bệnh này 368.834VND (95\%CI: -67.495 805.164; $p=0,098)$. Nghiên cứu ghi nhận mối tương quan giữa giá trị CP TTYT điêu trị suy tim nội trú với độ tuổi $(r=-0,068 ; p=0,000)$, số ngày điều trị $(r=0,428 ; p=0,000)$ và số lượt ngoại trú $(r=0,032 ; p=0,000)$.

Phân tích hồi quy tuyến tính đa biến bằng phương pháp đưa vào dần, nghiên cứu thu được kết quả trình bày trong bảng 4 .

Bảng 4. Mô hình hồi quy đa biến ( $R^{2}$ hiệu chỉnh $\left.=0,574 ; p<0,05\right)$

\begin{tabular}{|c|c|c|c|c|c|c|}
\hline \multirow{2}{*}{$\begin{array}{l}\text { Biến } \\
\text { phụ } \\
\text { thuộ́c }\end{array}$} & \multirow{2}{*}{$\begin{array}{c}\text { Hằng số/ } \\
\text { Biến độc lập }\end{array}$} & \multicolumn{2}{|c|}{ Hệ số chưa chuẩn hoá } & \multirow{2}{*}{$\begin{array}{c}\text { Hệ số chuấn } \\
\text { hóa } \\
\text { Beta } \\
\end{array}$} & \multirow[t]{2}{*}{$\mathbf{T}$} & \multirow[t]{2}{*}{ Sig. } \\
\hline & & B & SE & & & \\
\hline \multirow{9}{*}{$\begin{array}{l}\text { Ln } \\
\text { (tổng } \\
\text { chi phí) }\end{array}$} & Hằng số & 14,526 & 0,009 & & $1.643,211$ & 0,000 \\
\hline & Giới tính nam & 0,054 & 0,003 & 0,329 & 159,325 & 0,000 \\
\hline & Có đái tháo đường & 0,053 & 0,005 & 0,020 & 9,993 & 0,000 \\
\hline & Tuối & 0,001 & 0,000 & 0,021 & 10,163 & 0,000 \\
\hline & Số ngày điều trị & 0,048 & 0,000 & 0,627 & 189,440 & 0,000 \\
\hline & TTPT & 0,556 & 0,003 & 0,329 & 159,325 & 0,000 \\
\hline & Lượt ngoại trú & 0,103 & 0,001 & 0,191 & 91,417 & 0,000 \\
\hline & Cấp cứu & 0,099 & 0,004 & 0,059 & 28,115 & 0,000 \\
\hline & Nôi chuyến viên & 0,073 & 0,004 & 0,043 & 20,665 & 0,000 \\
\hline
\end{tabular}

Theo Bảng 5, nghiên cứu ghi nhận mô hình hồi quy tuyến tính có $R^{2}$ hiệu chỉnh có giá trị $0,574(p<0,05)$. CP TTYT một năm điều trị suy tim chịu ảnh hưởng bởi nhiêu yếu tố với mức độ ảnh hưởng giảm dần theo trình tự: Tiểu thuật phẩu thuật với $\beta_{k}=0,557(p<0,001)$; lượt ngoại trú $\left(\beta_{k}=0,103 ; p<0,001\right)$; cấp cứu $\left(\beta_{k}=0,099\right.$; $p<0,001)$; nội chuyển viện $\beta_{k}=0,073(p<0,001)$. Một số yếu tố khác có mức ảnh hưởng yếu hơn là giới tính nam với giá trị $\beta_{\mathrm{k}}=0,054(\mathrm{p}<0,001)$; có bệnh kèm đái tháo đường với $\beta_{k}=0,053$ $(p<0,001)$ và số ngày điều trị $\left(\beta_{k}=0,048\right.$ $(p<0,001)$. Tuổi có ảnh hưởng yểu nhất với $\beta_{k}=$ $0,001(p<0,001)$

Mô hình hồi quy tuyến tính đa biến thể hiện mối quan hệ giữa Ln (CPTTYT) với các thành phần có dạng:

\section{LN (Tống chi phí) $=14,503+0,557 *$ TTPT $+0,001 *$ Tuối $+0,053 * \mathrm{Nam}+0,045 *$ Sô ngày điều trị + 0,095 * Cấp cứu + 0,067 * Nội chuyên viên + 0,051 * Có tiêu đường + $0,104 *$ Lướt ngoại trú}

\section{BÀN LUÂN}

Theo kết quả khảo sát từ mẫu nghiên cứu gồm 111.926 ca điều trị suy tim trong dữ liệu 
thanh toán điện tử của bảo hiểm xã hội Việt Nam (BHXH VN) toàn quốc giai đoạn 2017 - 2018, tỷ lệ nam:nữ là $1: 1,30$. Tỷ lệ này phù hợp với nghiên cứu của Nguyễn Thà̀nh Tuyên với tỷ lệ nam ít hơn nữ [7]. Độ tuổi trung bình của người bệnh suy tim là $69,71 \pm 15,18$ tương đối phù hợp với nghiên cứu của Đố Thị Nam Phương tại Viện tim TP.HCM [8].

Về bệnh lý, Đề tài nghi nhận bệnh cao huyết áp kèm theo chiếm tỉ lệ cao $35 \%$, bệnh lý tiểu đường thấp hơn chiếm $11 \%$, kết quả này thấp hơn so với nghiên cứu của tác giả Nguyễn Thành Tuyên, nhau nhưng tỉ lệ bệnh lý cao huyết áp đều có tỉ lệ cao hơn bệnh lý tiểu đường [7]. Nghiên cứu còn ghi nhẩn số ngày điều tri mổi trung bình là $11,99 \pm 13,64$ ngày, kết quả này cao hơn so với nghiên cứu của tác giả Đố Thị Nam Phương ở Viên tim TP.HCM là 10,7 $\pm 9,9$ ngày [8]. Kết quả này có thể được giải thích bởi sự khác biệt trong phác đồ điều trị, số lượng giường bệnh và sự phát triển của các cơ sở chăm sóc trong cộng đồng cho người bệnh sau khi xuất viên.

Phân tích mối liên hê giữa các yếu tố nhân khẩu và bệnh lý đến giá trị tổng chi phí, đề tài ghi nhận có 8 yếu tố liên quan đến chi phí điều trị bao gồm: thủ thuật phẫu thuật, tuổi người bệnh, NAM (giới tính), số ngày điều trị, cấp cứu, nội chuyển viện, có tiểu đường, lượt ngoại trú. Trong đó yếu tố có sự ảnh hưởng mạnh nhất lên CP TTYT là thủ thuật phẫu thuật và số lượt ngoại trú.

Mặc dù dữ liệu thanh toán bảo hiểm y tế là nguồn dữ liệu lớn nhất, đáng tin cậy nhất tại Việt Nam ở thời điểm hiện tại, nghiên cứu dựa trên dữ liệu này có thể bỏ qua các đối tượng người bệnh điều trị ngoài bảo hiểm y tế vì vậy kết quả thu được có thể có giá trị khác khi phân tích thêm trên nhóm đối tượng này. Nghiên cứu mới chỉ dừng lại ở việc đánh giá CP TTYT do suy tim trong 1 nămm, chưa đánh giá được chi phí trực tiếp ngoài y tế và gián tiếp

\section{KẾT LUẬN}

Khảo sát trên 111.926 ca điều trị suy tim trên dữ liệu thanh toán điện tử của bảo hiểm xã hội Việt Nam toàn quốc giai đoạn 2017 - 2018 có độ tuổi trung bình là $69,71 \pm 15,18$ với tỷ lệ nam: nữ là $1: 1,30$, người bệnh có số ngày điều trị trung bình tại bệnh viện là $11,99 \pm 13,644$ ngày. Nghiên cứu ghi nhận mối liên hệ giữa tổng chi phí điều trị với thủ thuật phẫu thuật, tuổi người bệnh, giới tính, số ngày điều trị, cấp cứu, nội chuyển viện, có tiểu đường, lượt ngoại trú. Mô hình hồi quy tuyến tính đa biến thể hiện mối quan hệ giữa tổng chi phí mỗi đợt điều trị suy tim với các yếu tố liên quan đã được xây dựng với $R^{2}$ hiêu chỉnh là $0,574(p<0,05)$ và có dạng:

LN (Tống chi phí) $=14,503+0,557 *$ TTPT $+0,001 *$ Tuối $+0,053 * \mathrm{Nam}+0,045 *$ Sô ngày điều trị + 0,095* Cấp cứu + 0,067 * Nội chuyên viên + 0,051 * Có tiêu đường + $0,104 *$ Lướt ngoại trú

\section{TÀI LIẸU THAM KHẢO}

1. Nussbaumerová B., et al. (2018), "Diagnosis of heart failure: the new classification of heart failure", Vnitr Lek, 64(9), pp. 847-851.

2. Lesyuk W., et al. (2018), "Cost-of-illness studies in heart failure: a systematic review 20042016", BMC Cardiovasc Disord, 18(1), pp. 74.

3. Virani S. S., et al. (2020), "American Heart Association Council on Epidemiology and Prevention Statistics Committee and Stroke Statistics Subcommittee", Heart Disease and Stroke Statistics-2020 Update: A Report From the American Heart Association. Circulation, 141(9), pp. e139-e596

4. Mozaffarian D. et al. (2016), "Heart disease and Stroke Statistics-2016 Update: A Report From the American Heart Association", Circulation. 133 (4), pp. e38-360.

5. Cook C., et al. (2014), "The annual global economic burden of heart failure", Int J Cardiol, 171(3), pp. 368-376, doi: $10.1016 / j . i j c a r d .2013 .12 .028$.

6. Nguyễn Thị Thu Thủy, Trân Cát Đông, Trân Tiến Hưng. (2020)' "Phân tích chi phí trực tiếp y tế trong điểu trị mối ca nhập viện do suy tim từ dữ liệu thanh toán bảo hiểm y tế việt nam năm 20172018", Tap chí Y học Việt Nam, vol. 06/2020, no. 1, pp. 93-99.

7. Nguyễn Thành Tuyên, Võ Thị Xuân Hoa (2012). Khảo sát đặc điểm người bệnh suy tim cấp, Bệnh Viện Tim Mạch An Gianng.

8. Đố Thị Nam Phương, Nguyển Anh Duy Tùng (2019). Khảo sát các yếu tố tiên lượng tử vong trên bệnh nhân suy tim phân suất tống máu giảm nhập viện tại Viện tim TP.HCM, Tạp chí chuyên đề tim manh học của Hội Tim Mach TP. HCM.

9. Reyes E. B., et al. (2016), "Heart failure across Asia: same healthcare burden but differences in organization of care", Int. J. Cardiol, 223, pp. 163-167.

10. Bộ Y tế (2017), Quyết định số 6061/QĐ-BYT ngày 29/12/2017. Về việc ban hành "Bô mã danh mục dùng chung áp dụng trong khám bệnh, chữa bếnh và thanh toán bảo hiểm y tế" (phiên bản số 5).

11. Hội Tim Mạch Học Việt Nam (2015), Khuyến cáo của hôi tim mạch quổc gia Việt Nam về "Chẩn đoán và điều trị suy tim: câp nhật 2015".

12. Lesyuk W., et al. (2018), "Cost-of-illness studies in heart failure: a systematic review 20042016", BMC Cardiovasc Disord, 18(1), pp. 74.

13. Ponikowski P., et al. (2014), "Heart failure: preventing disease and death worldwide", ESC Heart Fail, 1(1), pp. 4-25. 